Available online on 15.05.2020 at jddtonline.info
Open Access to Pharmaceutical and Medical Research
unrestricted non-commercial use, provided the original work is properly cited

Open@ Access

Research Article

\title{
Statistical Retrospective Analysis of Spontaneous Abortions in Sidi Bel Abbes Region
}

\author{
Mellali Sarah ${ }^{* 1,2}$, Haoud Khadidja ${ }^{2}$, Bouguetaia mohammed el amin ${ }^{3}$, Diaf Mustapha ${ }^{2}$ \\ (1) SE \& SNV Institute, University Center Ahmed ZABANA; Bourmadia, Relizane. Algeria \\ (2) Department of Biology, Faculty of Natural and Life Sciences; Djillali Liabes University, Sidi Bel Abbès-Algeria \\ (3) Ouled Mohamed Chlef Hospital, Chlef, Algeria
}

\begin{abstract}
Objective: The aim of our study was to identify modifiable risk factors for miscarriage and to estimate the preventable proportion of miscarriages that could be attributed to these risks. Materials and Method: We carried out an epidemiological study of pregnancy loss in the Sidi Bel Abbes region from 2010 to 2015, with a total of 54720 livebirths and 4349 of spontaneous abortions (SA). The risk of spontaneous abortion related to the fetal loss age, maternal age; parity and previous spontaneous abortions was studied. Results: The rate of spontaneous abortions varies between $7 \%$ and $9 \%$ and appears to remain constant over the six years, with an average incidence of $8 \%$. We also observed a significant increase in the incidence of SA with the increase in maternal age. $77 \%$ of SA occurred before 12 weeks of gestation. The peak incidence occurred during the second month of pregnancy, between 6th and $10^{\text {th }}$, the rate of AS is the highest among primigests. The incidence of SRA in our study is within the range suggested by these different studies, with a SRA rate of 5\%. Fetal loss is high in women in their late 30 s or older, irrespective of reproductive history. Conclusion: The fact remains that the risk factors remain the same, namely, the increase in maternal age (inducing an increase in chromosomally unbalanced designs) and primigestity.
\end{abstract}

Keywords: Spontaneous, abortion, epidemiological, study, risk, factors.

Article Info: Received 12 March 2020; Review Completed 26 April 2020; Accepted 02 May 2020; Available online 15 May 2020

Cite this article as:

Mellali S, Haoud K, Bouguetaia MA, Diaf M, Statistical Retrospective Analysis of Spontaneous Abortions in Sidi Bel Abbes Region, Journal of Drug Delivery and Therapeutics. 2020; 10(3):202-206 http://dx.doi.org/10.22270/jddt.v10i3.4107

*Address for Correspondence:

Dr Mellali Sarah, SE \& SNV Institute, University Center Ahmed ZABANA; Bourmadia, Relizane. Algeria

\section{INTRODUCTION:}

Spontaneous miscarriage is a pregnancy that ends spontaneously before the fetus has reached a viable gestational age (fetal death before 24 weeks) ${ }^{1}$. Miscarriage could be considered one of the most frequent problems that could happen during the pregnancy in the human species 2 . Most studies report that around one in five clinical pregnancies will end in miscarriage 2, 3. Chromosomal abnormality of the fetus is involved in approximately half of the miscarriage, for which errors at meiosis caused by advanced maternal age at time of conception has been found to be a risk factor $\mathbf{4}, \mathbf{5}$. Indeed, most studies concerning the risk factors for spontaneous abortion have concluded that the predominant negative effects are those of advanced maternal age (with a clear increase in risk after 35 years) and previous spontaneous abortion 4,6,7,8. Nevertheless, there have been a lot of studies investigating other risk or etiologic factors: previous spontaneous abortions and multigravidity are also well known risk factors for spontaneous abortion in subsequent pregnancies 9,10. Several behavioural and social risk factors have been reported as increasing the risk of miscarriage, but most remain controversial or unconfirmed.

We aimed to realize an epidemiological study of pregnancy loss in the Sidi Bel Abbès region to identify modifiable risk factors for miscarriage and to estimate the preventable proportion of miscarriages that could be attributed to these.

\section{MATERIAL AND METHODS:}

We carried out a retrospective study based on the analysis of a sample of women who had undergone a spontaneous abortion (SA) and were admitted to the maternity ward of the Hassani Abdelkader hospital in Sidi Bel Abbés. Individual data sheets were compiled from the records of the patients recruited. Each record contained the following data: maternal age, gestational age, parity, gestures, history of spontaneous abortions. The characteristics of the sample are shown in Table 1. 
Table 1: Characteristics of the sample

\begin{tabular}{lc}
\hline & Sample \\
\hline Sample size & $54720 \mathrm{LB} / 4349 \mathrm{SA}$ \\
Average maternal age (years) & 31.47 \\
The youngest patient & $\mathbf{1 7}$ \\
Oldest patient & $\mathbf{6 0}$ \\
Middle Gestational Age (WA) & $\mathbf{1 0 . 9 6}$ \\
Youngest GA & $\mathbf{5}$ \\
Oldest GA & $\mathbf{2 4}$ \\
\hline
\end{tabular}

LB: Live birth, SA: spontaneous abortion, WA: weeks of amenorrhea, GA: gestational age

Statistical study: Statistical data capture and analysis was performed using software: Microsoft Office Excel 2007, IBM® Spss ${ }^{\circledR}$ statistics IBM Corp (version 20.0).

\section{RESULTS AND DISCUSSION:}

In our study, the incidence of spontaneous abortions was calculated in relation to the total number of pregnancies recorded annually during the study period (live births plus registered abortions). Table 2 shows, for our sample, the annual incidence of SA between 2010 and 2015. The rate of spontaneous abortions varies between $7 \%$ and $9 \%$ and appears to remain constant over the six years, with an average incidence of $8 \%$. Although the exact incidence of spontaneous abortions in a population is difficult to estimate, the rate we obtained is slightly below what is reported in the literature. Indeed, some authors place this incidence between 10 and $15 \%$ for clinically recognized pregnancies $\mathbf{1 1}$, 12, 13. Others estimate it at $20 \%$ thus affecting about one in five pregnancies $\mathbf{3 , 1 4}$. Others go so far as to presume that this rate could be 4 to 5 times higher whereas about two thirds of pregnancies fail, if we take into account sub-clinical pregnancies, that is, pregnancies that stop just after conception and biochemical pregnancies 13,14, 15.

These different data are not contradictory and explain the relatively low incidence of SA in our study. In fact, in general women do not consult or shortly before the end of the first trimester of pregnancy and a very large number of SA occur very early in pregnancy, before or at the time of implantation or before clinical discovery of gestation. In addition, women may present a wide variety of symptoms during a miscarriage and the number of spontaneous abortions at home, without any medical intervention, is unknown.

Table 2: Annual incidence of SA

\begin{tabular}{cccc}
\hline & Registered pregnancies & Spontaneous abortions & Rate \% \\
\hline $\mathbf{2 0 1 0}$ & 8199,00 & 721 & $9 \%$ \\
$\mathbf{2 0 1 1}$ & 9333,00 & 708 & $8 \%$ \\
$\mathbf{2 0 1 2}$ & 9181,00 & 714 & $8 \%$ \\
$\mathbf{2 0 1 3}$ & 9015,00 & 717 & $8 \%$ \\
$\mathbf{2 0 1 4}$ & 9883,00 & 713 & $7 \%$ \\
$\mathbf{2 0 1 5}$ & 10528,00 & 776 & $7 \%$ \\
\hline
\end{tabular}

\section{Distribution of SA by maternal age:}

Most studies on risk factors for spontaneous abortions concluded that the predominant negative effects are those of advanced maternal age (with a marked increase in risk after 35 years) 4,6,7,8, 16. However, reproductive behaviour in our society has changed and, for various social reasons (education, work, late marriage, etc.), many women choose to delay motherhood. For example, according to UK census data, the number of babies born to mothers aged 35 or over doubled between 1985 and 2001, from $8 \%$ to $16 \%$ of total births 17, 18. In the United States, this proportion increased from $19 \%$ in 1976 to $37.4 \%$ in 1998 19, 20. Although there is no comparable data for spontaneous abortions, it is logical to think that this rate has also increased.

Indeed, a large prospective study has shown that maternal age at conception is a strong risk factor for SA 4 due to an increase in chromosomally abnormal designs $\mathbf{1 7 , 2 1}$, thus, the risk of fetal loss increases significantly after the age of 354 . In our study, we also observed a significant increase in the incidence of SA with the increase in maternal age, from $7.2 \%$ in patients aged $25-29$ to $10 \%$ in patients aged $35-39$ and $14 \%$ in patients aged $40-45$ (Table 3).

Table 3: Distribution of SA by maternal age

\begin{tabular}{cccc}
\hline Maternal age (years) & Number of cases & Rate $\%$ & Incidence \%* \\
\hline$<\mathbf{1 9}$ & 88 & $2 \%$ & $7 \%$ \\
$\mathbf{2 0}-\mathbf{2 4}$ & 695 & $16 \%$ & $7,1 \%$ \\
$\mathbf{2 5}-\mathbf{2 9}$ & 1000 & $23 \%$ & $7,2 \%$ \\
$\mathbf{3 0}-\mathbf{3 4}$ & 1000 & $23 \%$ & $8,2 \%$ \\
$\mathbf{3 5}-\mathbf{3 9}$ & 913 & $21 \%$ & $10 \%$ \\
$\mathbf{4 0}-\mathbf{4 5}$ & 609 & $14 \%$ & $14 \%$ \\
$<\mathbf{4 6}$ & 44 & $1 \%$ & $13 \%$ \\
\hline
\end{tabular}

*Number of new cases/ total population 
This is consistent with the results of literature $\mathbf{4 , 8 , 2 2 , 2 3}$. The probability of a successful pregnancy in women aged 40 or over is therefore low, with risks of miscarriage, extra-uterine pregnancy, or a much higher stillbirth than in women in their thirties 4 . The observed association between maternal age and increased SA may be the result of age-related changes, such as an increase in chromosomal imbalances, a lower quality of the uterine mucosa which penalizes the implantation of the egg or an alteration of hormonal functions. In addition, age may be a factor in increasing exposure to unknown risk factors $\mathbf{2 1 , 2 2}$.

\section{Repartition of SA by gestational age:}

Figure 1 shows the distribution of SA by gestational age. SA are generally classified as early AS (occurring before the 12th SA) and late AS (occurring between the 12th and the 24 th SA 24 . The vast majority of SA occurs early, before 12 SA 24, 25, 26. Mattar and Mendes (2002) 27 estimate that $80 \%$ of SA occurs before the end of the first trimester of pregnancy. This is consistent with our population, where $77 \%$ of SA occurred before 12 weeks of gestation.

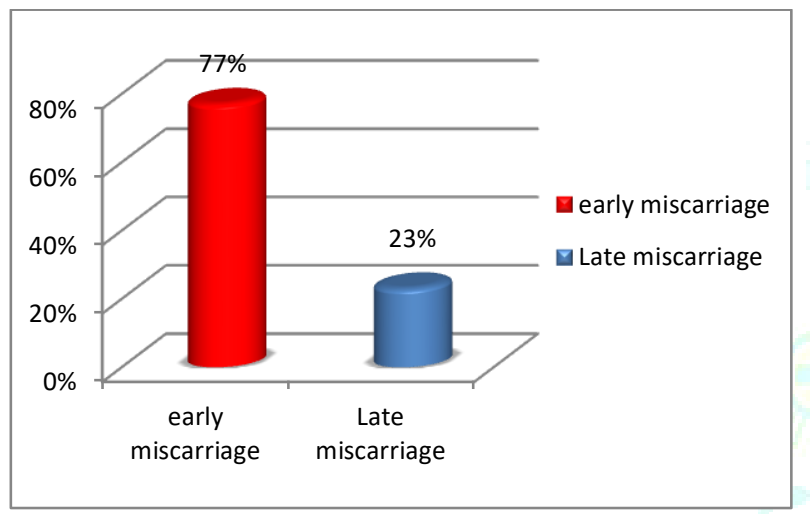

Figure 1: Rate of early and late miscarriage

In our study, the peak incidence occurred during the second month of pregnancy, between 6th and 10th week of amenorrhea (WA), with an incidence of only $40 \%$ for this period (Figure 2). This is similar to that of Bjorn and his colleagues (2011) ${ }^{28}$ where the SA incidence peak is between
7 th and 11th SA. The proportion of $1 \%$ recorded in the first month is clearly due to under-diagnosis, since women do not usually consult before the fourth week of pregnancy and embryo losses are not recorded. After the 12th SA, Figure 2 shows the passage of the SA rate below 5\%. These results are consistent with those obtained by Brigham and colleagues (1999) 24 , who found that less than $5 \%$ of SA occurred after identification of embryonic heart activity, that is, after the first ultrasound at 12th week of amenorrhea.

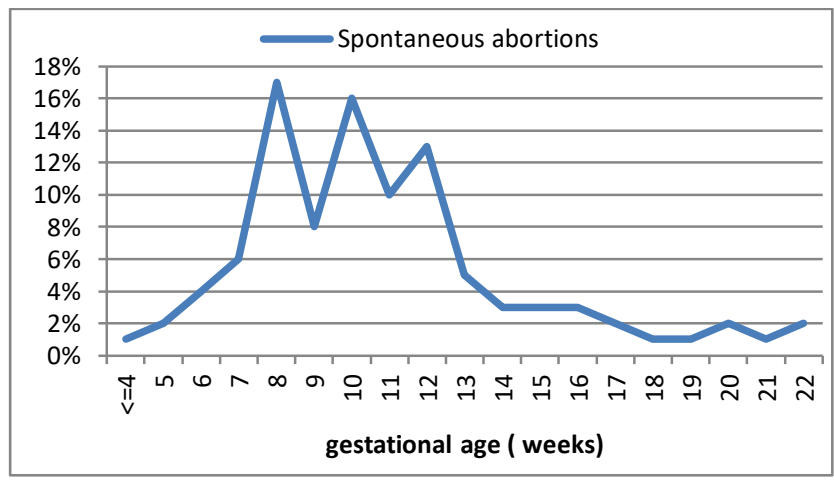

Figure 2: Repartition of SA by gestational age

\section{Distribution of SA based on parity:}

Reproductive history is a predictive factor independent of the future outcome of pregnancy. Although most studies refer to pluriparity as a known risk factor for SA 9, 10, 29, graphs obtained at Sidi Bel Abbés (Table 4) contradict this theory in the first analysis. Our study shows, in fact, that for our sample the rate of AS is the highest among primigests, with $31 \%$ of SA. This result is not in contradiction with the literature data; indeed, in our study, we studied the distribution and not the incidence of SA according to parity, knowing that the number of SA is becoming less and less important as parity increases. These results are nevertheless supported by a Swedish study conducted by Raymond and colleagues (1996) ${ }^{30}$ which states that the risk of SA is higher among nullipares, even when the analysis excludes hypertensive women, diabetic, with placental complications or intrauterine growth retardation.

Table 4: Distribution of SA based on parity

\begin{tabular}{ccc}
\hline Parity & Number of cases & Spontaneous abortions \% \\
\hline 0 & 1348 & $31 \%$ \\
1 & 1043 & $24 \%$ \\
2 & 870 & $20 \%$ \\
3 & 522 & $12 \%$ \\
4 & 305 & $7 \%$ \\
$>=5$ & 261 & $6 \%$ \\
\hline
\end{tabular}

\section{Breakdown of SA according to their repetition:}

According to the Royal College of Obstetricians and Gynecologists (1998) and the American College of Obstetricians and Gynecologists (2001) 31, 32, spontaneous repeated abortions (SRA) are often defined as the occurrence of at least three consecutive pregnancy losses before the 24 th week of amenorrhea. In nearly $50 \%$ of cases, the etiology of SRA remains unknown 33 , however, the known risk factors for SRA are genetic disorders, in particular parental chromosomal abnormalities that represent a significant etiology, with a prevalence of these abnormalities ranging from $2 \%$ to $8 \%$ in couples with SRA ${ }^{34}$, uterine pathologies, endocrine dysfunctions, autoimmune diseases, thrombophilia, and environmental factors $\mathbf{3 5}$.

Most studies on the subject estimate the incidence of SRA in women of reproductive age between 1 and 5\% 17, 36, 37,38,39. This frequency increases with subsequent accidents: 17-35 $\%$ after two SA, 25-46 \% after three SA and more than $50 \%$ after six SRA. The incidence of SRA in our study is within the range suggested by these different studies, with a SRA rate of 
5\% (Table 5). The increase in the risk of SA with the number of previous accidents is an argument in favour of the reality of SRA syndrome. It is estimated that the probability of having a live child decreases by $23 \%$ for each additional abortion beyond three abortions ${ }^{\mathbf{1 7}}$. Normally, it is necessary to wait for the occurrence of three SA (definition of SRA) to undertake an etiological assessment. However, even by resisting the legitimate pressure of couples "to find a cause, and therefore propose treatment", this SRA assessment is often performed after two SA because recidivism rates after 2 or 3 SA are close. The primary role of the practitioner is first of all to reassure the couple that the likelihood of successful pregnancy after three SA is $60 \%$.

Table 5: Breakdown of SA according to their repetition

\begin{tabular}{ccc}
\hline Antecedent of miscarriage & Number of cases & Rate $\%$ \\
\hline Without antecedent & 2978 & 68.47 \\
$\mathbf{1}$ miscarriage & 939 & 21.59 \\
$\mathbf{2}$ miscarriage & 276 & 6.34 \\
$\mathbf{3}$ miscarriage & 108 & 2.48 \\
$\mathbf{4}$ miscarriage & 27 & 0.62 \\
$>=5$ miscarriage & 18 & 0.41 \\
\hline
\end{tabular}

\section{CONCLUSION}

It is clear from our study that the situation of SA in the Sidi Bel Abbès region does not depart from the conclusions of previous studies conducted around the world. Indeed, although the incidence of SA is relatively lower than the statistics, the fact remains that the risk factors remain the same, namely, the increase in maternal age (inducing an increase in chromosomally unbalanced designs) and primigestity. We were also able to conclude that the majority of SA occurred early in pregnancy and that the ASR rate was within the $2-8 \%$ advanced by most studies on the subject.

\section{CONFLICT OF INTEREST:}

The authors declare no conflict of interest.

\section{ACKNOWLEDGEMENTS}

The authors would like to express their gratitude to all the participants for their valuable assistance in this study.

\section{REFERENCES:}

1. Regan L and Rai R, Epidemiology and the medical causes of miscarriage. Best Practice \& Research Clinical Obstetrics \& Gynaecology, 2000; 14:839-54.

https://www.ncbi.nlm.nih.gov/pubmed/11023804 ; DOI: 10.1053/beog.2000.0123

2. Garcia-Enguidanos A, Calle ME, Valero J, Luna S, DominguezRojas V, Risk factors in miscarriage: a review. European Journal of Obstetrics \& Gynecology, 2002; 102:111-19. https://www.ncbi.nlm.nih.gov/pubmed/11950476 ; DOI: 10.1016/s0301-2115(01)00613-3

3. Savitz DA, Hertz-Picciotto I, Poole C, Olshan AF, Epidemiologic measures of the course and outcome of pregnancy. Epidemiologic Reviews, 2002; 24:91-101.

https://www.ncbi.nlm.nih.gov/pubmed/12762085 ; DOI: 10.1093/epirev/mxf006

4. NyboAndersen AM, Wohlfahrt J, Christens P, Olsen J, Melbye M, Maternal age and fetal loss: population based register linkage study. British Medical Journal, 2000; 320(7251):17081712.

https://www.ncbi.nlm.nih.gov/pubmed/?term=Maternal+age +and+fetal+loss $\% 3 \mathrm{~A}+$ population+based+register+linkage+st udy; DOI: $10.1136 /$ bmj.320.7251.1708

5. Simpson JL, Causes of fetal wastage. Clinical Obstetrics and Gynecology, 2007; 50:10-30.

https://www.ncbi.nlm.nih.gov/pubmed/17304022 ; DOI:10.1097/GRF.0b013e31802f11f6.
6. Coste J, Job-Spira N and Fernandez H, Risk of factors for spontaneous abortions: a case control study in France. Human Reproduction, 1991; 6:1332-1337.

https://www.ncbi.nlm.nih.gov/pubmed/1752937 . DOI: 10.1093/oxfordjournals.humrep.a137535.

7. Fretts RC, Shmittdil J, Mclean FH et al., Increase maternal age and the risk of fetal death. The New England Journal of Medicine, 1995; 333:953-957.

https://www.ncbi.nlm.nih.gov/pubmed/7666913. DOI:10.1056/NEJM199510123331501.

8. Osborn JF, Cattaruzza MS and Spinelli A, Risk of spontaneous abortion in Italy, 1978-1995 and the effect of maternal age, gravidity, marital status and education. American Journal of Epidemiology, 2000; 151:312-313.

https://www.ncbi.nlm.nih.gov/pubmed/10625179/?utm_sou rce=gquery\&utm_medium=referral\&utm_campaign=CitationS ensor. DOI:10.1093/oxfordjournals.aje.a010128

9. Naylor AF and Warburton D, Sequential analysis of spontaneous abortion. In: collaborative study data show that gravidity determines a very substantial rise in risk. Fertility Sterility, 1979; 31:282-286.

https://www.ncbi.nlm.nih.gov/pubmed/437160/?utm_sourc e=gquery\&utm_medium=referral\&utm_campaign=CitationSen sor. PMID: 437160

10. Christiansen O, Epidemiological, immunogenetic and immunotherapeutic aspects of unexplained recurrent miscarriage. Danish medical bulletin, 1997; 44:396-424 https://www.ncbi.nlm.nih.gov/pubmed/9377902/?utm_sour ce=gquery\&utm_medium=referral\&utm_campaign=CitationSe nsor. PMID: 9377902

11. Kline J. Stein Z, Susser M. Conception to birth-epidemiology of prenatal development. Monographs in Epidemiology and Biostatistics. Oxford, Oxford University Press, 1989. https://www.amazon.com/Conception-Birth-EpidemiologyDevelopment-Biostatistics/dp/0195042867.

12. Chard T. Frequency of implantation and early pregnancy loss in natural cycles. Clinical Obstetrics and Gynecology, 1991; 5:179-89.

https://www.ncbi.nlm.nih.gov/pubmed/1855339/?utm_sour ce=gquery\&utm_medium=referral\&utm_campaign=CitationSe nsor. DOI: 10.1016/s0950-3552(05)80077-x.

13. Rai R and Regan L, Recurrent miscarriage. Lancet, 2006; 368:601-11.

https://www.ncbi.nlm.nih.gov/pubmed/16905025. DOI: 10.1016/S0140-6736(06)69204-0

14. Merviel P, Lanta S, Allier G, Gagneur O, Najas S. et al. Avortements spontanés à répétition. EMC-Gynécologie 
Obstétrique, 2005; 2:278-296. https://www.emconsulte.com/en/article/747893. Doi : 10.1016/S02461064(13)59740-4.

15. Jauniaux E and Burton GJ, Pathophysiology of Histological Changes in Early Pregnancy Loss. Placenta, 2005; 26:114-123. https://www.ncbi.nlm.nih.gov/pubmed/15708112.DOI: 10.1016/j.placenta.2004.05.011

16. Glinianaia SV, Rankin J, Bell R, Pearce MS, Parker L, Temporal changes in the distribution of population risk factors attenuate the reduction in perinatal mortality. Journal of Clinical Epidemiology, 2005; 58(12):1299-1307. https://www.academia.edu/13030095/Temporal_changes_in _the_distribution_of_population_risk_factors_attenuate_the_re duction_in_perinatal_mortality

17. Stirrat GM. Recurrent miscarriage. Lancet, 2007; 336:673-75. https://www.ncbi.nlm.nih.gov/pubmed/1975862. DOI: 10.1016/0140-6736(90)92159-f.

18. Sullivan AE, Silver RM, LaCoursiere DY, Porter TF, Branch DW:Recurrent fetal aneuploidy and recurrent miscarriage. Obstetetrical Gynecology, 2004; 104:784-788. https://www.ncbi.nlm.nih.gov/pubmed/15458902. DOI: 10.1097/01.AOG.0000137832.86727.e2

19. Ventura SJ, Taffel SM and Mosher WD, Estimates of pregnancies and pregnancy rate for the United-States: 19761985. American Journal of Public Health, 1988; 78:506-511. https://www.ncbi.nlm.nih.gov/pubmed/3354731. DOI: 10.2105/ajph.78.5.506

20. Guyer B, Hoyert DL, Martin JA et al. Annual summary of vital statistics-1998-. Pediatrics, 1999; 104:1229-1246. https://pediatrics.aappublications.org/content/104/6/1229/ tab-figures-data; DOI: 10.1542/peds.104.6.1229.

21. Cano F, Simon C, Remohi J, Pellicer A, Effect of ageing on the female reproductive system: evidence for a role of uterine senescence in the decline in female fecundity. Fertility and Sterility, 1995; 64:584-589. https://www.ncbi.nlm.nih.gov/pubmed/7543864; DOI:10.1016/s0015-0282(16)57797-8

22. Dominguez V, Calle E, Ortega $P$ et al. Adjusting risk factors in spontaneous abortion by multiple logistic regressions. European Journal of Epidemiology, 1991; 78:171-174. https://www.ncbi.nlm.nih.gov/pubmed/2044715; DOI: $10.1007 /$ bf00237362

23. Brigham S, Conlon C, Farquharson RG. A longitudinal study of pregnancy outcome following idiopathic recurring miscarriage. Human Reproduction, 1999; 14:2868-2871. https://www.ncbi.nlm.nih.gov/pubmed/10548638; DOI:10.1093/humrep/14.11.2868

24. Bricker L and Farquharson RG, Types of pregnancy loss in recurrent miscarriage: implications for research and clinical practice. Human Reproduction, 2002; 17:1345-1350. https://europepmc.org/article/med/11980763; DOI:10.1093/humrep/17.5.1345

25. Ugwumadu A, Manyonda I, Reid F, Hay P, Effect of early oral clindamycin on late miscarriage and preterm delivery in asymptomatic women with abnormal vaginal flora and bacterial vaginosis: a randomized controlled trial. Lancet, 2003; 361:983-988.

https://www.ncbi.nlm.nih.gov/pubmed/12660054; DOI :10.1016/S0140-6736(03)12823-1

26. Mattar R and Mendes ET. Abortion. In: Camano L et al. (eds) Obstetrics, 1st edn. Manole, São Paulo, 2002. https://accessmedicine.mhmedical.com/content.aspx?bookid $=1057 \&$ Sectionid $=59789157$.
27. Bjørn AM, Nørgaard M, Hundborg HH, Nohr EA, Ehrenstein V, Use of prescribed drugs among primiparous women: an 11year population-based study in Denmark. Clinical Epidemiology, 2011; 3:149-56. https://www.ncbi.nlm.nih.gov/pubmed/21607016. DOI:10.2147/CLEP.S17747

28. Czeizel A, Bognar Z and Rocckenbauer M, Some epidemiological data on spontaneous abortion in Hungary, 1971-80. Journal of Epidemiology and Community Health, 1984; 38:143-148. https://www.ncbi.nlm.nih.gov/pubmed/1912381. DOI:10.1016/0753-3322(91)90025-o.

29. Raymond EG, Cnattingius S, Kiely JL, Effects of maternal age, parity, and smoking on the risk of stillbirth. British Journal of Obstetrics and Gynaecology, 1994; 101(4):301. https://www.ncbi.nlm.nih.gov/pubmed/8199075. DOI:10.1111/j.1471-0528.1994.tb13614.x

30. Royal College of Obstetricians and Gynecologists. The management of recurrent miscarriage. Guideline no. 17 London: Royal College of Obstetricians and Gynecologists, 1998.

https://www.rcog.org.uk/globalassets/documents/guideline s/gtg_17.pdf

31. The American College of Obstetricians and Gynecologists. Bylaws Obstetrics \& Gynecology: May 2001; 98(1):186-192.

32. Stephenson MD, Awartani KA, Robinson WP, Cytogenetic analysis of miscarriages from couples with recurrent miscarriage: a casecontrol study. Human Reproduction, 2002; 17:446-510.

https://www.ncbi.nlm.nih.gov/pubmed/11821293. https://doi.org/10.1093/humrep/17.2.446

33. Elghezal H, Hidar S, Mougou S, Khairi H, Saad A, Prevalence of chromosomal abnormalities in couples with recurrent miscarriage. Fertility Sterility, 2007; 88:721-3. https://www.fertstert.org/article/S0015-0282(06)047054/fulltext. DOI:10.1016/j.fertnstert.2006.11.160

34. Regan L. Recurrent miscarriage. British Medical Journal, 1991; 302:543-44.

https://www.bmj.com/content/302/6776/543.DOI: 10.1136/bmj.302.6776.543.

35. Carrington B, Rai R, Regan L, Polycystic ovaries, insulin resistance, hypofibrinolysis and recurrent miscarriage. Journal of the Society for Gynecologic Investigation, 2005; 12 : 20.

36. Hogge WA, Byrnes AL, Lanasa MC, Surti U, The clinical use of karyotyping spontaneous abortions. American Journal of Obstetrics and Gynecology, 2003; 189:397-400. https://www.ncbi.nlm.nih.gov/pubmed/14520206. DOI:10.1067/s0002-9378(03)00700-2.

37. Coulam CB, Epidemiology of recurrent spontaneous abortion. American Society for Reproductive Immunology, 1991; 26:237. https://onlinelibrary.wiley.com/doi/abs/10.1111/j.16000897.1991.tb00697.x. DOI: 10.1111/j.16000897.1991.tb00697.x

38. Scott JR, Rote NS, and Branch DW, Immunologic aspects of recurrent abortion and fetal death. Obstetrics \& Gynecology, 1987; 70:645-656.

https://www.ncbi.nlm.nih.gov/pubmed/3114693. PMID: 3114693.

39. Ogasawara M, Aoki K, Okada S, Suzomori K, Embryonic karyotype of abortuses in relation to the number of previous miscarriages. Fertility Sterility, 2000; 73:300-4. https://www.ncbi.nlm.nih.gov/pubmed/10685533. DOI:10.1016/s0015-0282(99)00495-1. 